\title{
Ambiguity when Playing Coordination Games Across Cultures
}

\author{
Joanne Laban-Peryman* \\ Behavioural Business Lab, RMIT University \\ David Kelsey \\ University of Exeter Business School
}

06 August 2019

Abstract: We investigate how people coordinate within their own cultures, compared to interactions with people from different cultures. As players are likely to experience more ambiguity when playing a different culture, we expect players to choose safer strategies. We run experiments with a stag hunt and bargaining coordination game. Using a between-subjects design, we vary the identity of the opponent between someone of the same culture or a different culture. We compare the responses of British and East Asian students at the University of Exeter and show the cultural identity of the opponent by physical appearance. The players appear to use cultural stereotypes to predict behaviour, especially in the bargaining game which may require more strategic thought than the stag hunt game. In particular, the British act as though East Asians would behave more cautiously than other British. According to our results, the stereotype of East Asians being cautious is misleading.

*Corresponding author, email: jo.peryman@rmit.edu.au

Acknowledgments: We are grateful to Miguel Fonseca, Brit Grosskopf, Simon Gächter, Jürgen Eichberger, and seminar participants at the University of Exeter, the FUR Conference, and the ESA World Meetings for valuable suggestions and feedback. We would also like to thank Anna Morozova and Bing Chao for assistance in running the experiments. Finally, we thank the University of Exeter's Behaviour, Decisions and Markets research centre for funding our experiments. 


\section{Introduction}

Coordination is important for many economic decisions, such as firms deciding on output and pricing decisions without knowing the decisions of their competitors, or Governments setting trade policy without knowing the strategies of other countries. People from different backgrounds may use different heuristics when trying to coordinate with others. Knowing how culture affects the ability to coordinate will be useful for those engaging in trade or competition with people from other countries.

People from the same culture are likely to share similar norms and perhaps find it easier to predict the behaviour of their opponent, thus improving coordination. On the other hand, when playing against someone from a different culture, the players may be unfamiliar with each other's norms and need to rely on cultural stereotypes to try and predict the opponent's behaviour. We expected players to experience more ambiguity when playing against someone from a different culture and therefore choose safer strategies in coordination games.

We ran two types of coordination games - a stag hunt and a bargaining game. While we did not find East Asian students to differentiate very much between a British or East Asian opponent, the British students tended to act very differently against an East Asian opponent compared to a British opponent. In a stag hunt game, the British students played the safer strategy more often against an East Asian opponent, while in a bargaining game they demanded more of the pie. The British seemed to be basing their behaviour on a cultural stereotype that East Asians are cautious. However, our results show that this stereotype is misleading. 


\section{Background Literature}

Although cultural differences in coordination games have not yet been studied extensively, some related literature has demonstrated the importance of social norms (e.g. Singh, 2012) and group identity (e.g. Benjamin et al, 2010; Chen and Chen, 2011; Chen et al, 2014) for coordination game outcomes. As culture is one aspect of identity, we can expect a group identity to be stronger when players are from the same cultural background. Chen and Chen (2011) show that a salient group identity increases coordination on Pareto superior outcomes in the minimum effort coordination game. As Chen and Chen impose only minimal group identities in the $l^{1} b^{1}$, we can expect natural group identities such as culture to have an even stronger effect. Similarly, social norms are culture specific, and norms of sharing and cooperation within a community are likely to increase efficiency in coordination games such as the stag hunt (Singh, 2012). Finally, expectations and beliefs are also important in coordination game decisions. When playing against someone from another culture, people may find it harder to predict their opponent's behaviour and need to rely on stereotypes when forming their beliefs (Fershtman and Gneezy, 2001; Hsee and Weber, 1999).

\subsection{Social Norms}

Singh (2012) considers how norms of trust within a society will affect behaviour in the stag hunt game. Typical payoffs for a two-player stag hunt game are illustrated below in Figure 1. The story goes as follows. Players must choose whether to hunt a stag or a hare when out hunting. Capturing a stag is more valuable than a hare but requires the help of both players. Therefore, if a player hunts a stag without the assistance of the

\footnotetext{
${ }^{1}$ Minimal groups are where participants are randomly allocated to groups and given an arbitrary label such as the "blue" or "yellow" group.
} 
other player, he will receive a payoff of zero. Capturing a hare is easier and guarantees a small but sure payoff. We assume that players are separated and cannot communicate while on the hunt, thus coordination is important for reaching an equilibrium.

Figure 1: Stag Hunt Game

\begin{tabular}{|c|c|c|c|}
\hline & \multicolumn{2}{|c|}{ Player 2} \\
\hline & & Stag & Hare \\
\hline \multirow[t]{2}{*}{ Player 1} & Stag & 2,2 & 0,1 \\
\hline & Hare & 1,0 & 1,1 \\
\hline
\end{tabular}

There are two pure strategy Nash equilibria in this game. The payoff dominant equilibrium is where all players help in hunting a stag and obtain maximum payoffs. However, there is also a risk dominant equilibrium, where each player guarantees him or herself a sure payoff from hunting a hare. There is also a mixed strategy equilibrium, where each player hunts stag or hare with a certain payoff-dependent probability. According to Singh (2012), people from societies with a norm of high trust are more likely to coordinate on the payoff dominant outcome, whereas people from societies with a norm of low trust will be driven towards the risk dominant equilibrium. This is because in a low trust society, people expect that the other player will be untrusting and prefer to guarantee themselves a hare. Therefore, their best response is to also hunt hare to avoid ending up with nothing.

Using data from the World Values Survey, Singh (2012) concludes that $64 \%$ of countries are characterised by low trust. In particular, countries with the lowest level of trust include African countries such as Uganda and Tanzania, whereas Scandinavian countries such as Denmark and Sweden have the highest levels of trust (Singh, 2012). Trust is particularly important in societies that lack formal contracts and enforcement 
mechanisms. In such societies, trust provides an incentive to engage in business deals as people can expect to be fairly compensated for their actions.

Singh develops a theory of how people base their expectations of others' behaviour on a sample of past interactions. A society will then converge towards either a low or high trust norm, which respectively correspond to the risk dominant and payoff dominant equilibria in the stag hunt game. We can think of the mixed strategy equilibrium as a society with a norm of medium trust. However, the medium trust society is highly unstable. As people update their expectations of others' behaviour after each interaction, a few successive positive or negative interactions could push the society towards either the high or low trust equilibrium. In such a society, monitoring and enforcement could be used to prevent convergence to the low trust equilibrium.

Singh's theory of how trust norms affect coordination in the stag hunt has not yet been empirically tested. We can expect people from collectivist cultures, such as China and India (Hofstede, 1980), to have norms of working together and sharing in the community, which may increase coordination on the payoff dominant outcome.

\subsection{Group Identity}

Identity was introduced into economic models by Akerlof and Kranton (2000), who theoretically show that people like to behave in a way that reinforces their identity. Extending this idea, Chen and Chen (2011) experimentally find that a common group identity $^{2}$ increases coordination on the payoff dominant equilibrium in a minimum effort game (Huyck et al, 1990), but only when the group identity is made salient. They make the group identity salient by allowing participants to communicate in their groups

\footnotetext{
2 Using randomly assigned minimal groups, which are labelled according to colour.
} 
when trying to solve a task where they have to match paintings to the respective artists. If participants help each other in the communication stage, the authors suggest they will be more likely to reciprocate when playing the minimum effort coordination game.

Worth noting, is that an increase in efficiency may also be driven by a shift in beliefs about the underlying probability distribution of the other players' actions, rather than an increase in altruism. Perhaps some participants in Chen and Chen's (2011) study decided to go for the payoff dominant outcome because they believed the other players were more likely to do the same after the communication stage. Therefore, as well as a potential increase in the other-regarding parameter, the beliefs about probabilities regarding the other players' behaviour is another factor that needs to be considered in explaining Chen and Chen's (2011) results.

\subsection{Expectations and Stereotypes}

Expectations of other peoples' behaviour may rely on stereotypes, which do not necessarily represent the social norm ${ }^{3}$. For example, Fershtman and Gneezy (2001) find that men of Eastern Jewish origin (Asian or African) in Israel are discriminated against in a trust game because they have an ethnic stereotype of being untrustworthy. However, the stereotype was found to be unjustified in the trust game as Eastern Jewish participants did not send back significantly lower amounts than men of European or American Jewish origin. They also find men of Eastern Jewish origin to be allocated more money in an ultimatum game because they have a stereotype of reacting harshly to unfairness. Again, this stereotype was unfounded in actual rejection rates.

\footnotetext{
3 Stereotypes are often correlated with social norms, as people gain utility from belonging to a group and thus often prefer to conform to group stereotypes in order to reinforce their group membership (Geisinger, 2004; Shih et al, 1999).
} 
Similarly, Hsee and Weber (1999) find predictions of risk aversion in Chinese and American participants to be in contrast to actual behaviour. Participants apparently rely on a misleading cultural stereotype that Americans are more risk seeking than Chinese, probably because Americans are portrayed as risk seeking in movies. In fact, the results show the opposite - Chinese are more risk seeking than Americans in financial lottery choice tasks when asked to choose between a certain outcome and a gamble. However, the predictions of participants in Hsee and Weber's (1999) experiment are not made salient by paying people for correct predictions.

Participants in Hsee and Weber's (1999) study apparently rely even more on the misleading stereotype when trying to predict behaviour of those from a different culture. The Chinese participants expected Americans to be even more risk seeking than the American participants expected of each other. Similarly, the American participants expected the Chinese to be even more cautious than the Chinese expected of other Chinese. When trying to predict behaviour of people in other countries, participants have less scope to base their prediction on people they know, and thus rely more on stereotypes. This suggests that people will likely face more ambiguity when interacting with those from another culture.

\subsection{Ambiguity and Coordination Games}

Ambiguity refers to a situation where the relevant probabilities are unknown and cannot be estimated to a reasonable degree. Eichberger et al (2008) show that the identity of the opponent matters for ambiguity, with participants experiencing more ambiguity when playing strategic games against a granny than a game theorist. Most students reported that the game theorist's behaviour was easier to guess than the granny and that they would prefer to play against the game theorist. As such, the 
students chose more ambiguity-averse strategies against the granny than the game theorist. As people are less familiar with the social norms of other cultures, perhaps they will experience more ambiguity when playing strategic games and therefore choose safer strategies.

A high degree of ambiguity can hinder coordination on the payoff dominant outcome in many coordination games. Eichberger and Kelsey (2002) consider a bargaining game where players can make claims on a total payoff, say 4 , but if the claims exceed 4, everyone receives 0 . As the players are not allowed to communicate, the game can be interpreted as a coordination game. Any outcome that exhausts the available surplus is a Nash equilibrium. However, with sufficient ambiguity, participants will prefer to claim lower amounts, leading to inefficient outcomes. The two-player version of this bargaining game where players can claim 1, 2, or 3 is illustrated below in Figure 2.

Figure 2: Bargaining Coordination Game Player 2

\begin{tabular}{cc|c|c|c|} 
& \multicolumn{2}{|c}{3} & \multicolumn{1}{c}{2} & 1 \\
\cline { 3 - 5 } Player 1 & 3 & 0,0 & 0,0 & 3,1 \\
\cline { 3 - 5 } & 2 & 0,0 & 2,2 & 2,1 \\
\cline { 3 - 5 } & 1 & 1,3 & 1,2 & 1,1 \\
\cline { 3 - 5 } & & &
\end{tabular}

As people are likely to experience a higher degree of ambiguity when playing against someone from another culture, we can expect such games to result in inefficient equilibria. However, social norms may also govern behaviour. For example, people from societies where fairness or equality is highly valued may select the efficient equilibrium of $(2,2)$ as a focal point. Similarly, those from trusting cultures may find it easier to 
coordinate on an efficient outcome, as in the stag hunt game discussed above. In contrast, those from low trust cultures may be driven towards inefficient outcomes such as $(1,1)$. To allow ambiguity and social norms to have maximum effect, we need to remove any obvious focal points when testing this game experimentally.

The bargaining game discussed above differs from the stag hunt in that the bargaining game is a situation of strategic substitutes, whereas the stag hunt is a game with strategic complements. Eichberger and Kelsey (2002) show that the implications of ambiguity differ depending on whether a game has strategic substitutes or strategic complements. Strategic substitutes are where an increase in the opponent's action will decrease the marginal benefit of one's own action. For example, in the bargaining game above, a larger claim of the opponent decreases the marginal benefit of one's own claim. Strategic complements are the opposite: an increase in the opponent's action makes one's own action more beneficial, as in the stag hunt game. If the opponent switches from hunting hare to hunting stag, this increases the benefit of putting in the extra effort to hunt stag.

Eichberger and Kelsey (2002) show that an increase in ambiguity will have opposite effects in games with strategic complements and substitutes, but this depends on whether there are positive or negative externalities. In the bargaining game we have negative aggregate externalities, because an increase in demand of the opponent lowers payoffs. Under negative externalities, in a game with strategic substitutes (e.g. the bargaining game), an increase in ambiguity will lower equilibrium actions. However, the opposite result holds under positive externalities. With strategic complements, an increase in ambiguity will increase equilibrium actions under negative externalities, but decrease equilibrium actions under positive externalities. The stag hunt game has 
positive externalities, i.e. a higher action by the opponent is beneficial, which means that ambiguity should lower equilibrium actions in the game, leading to the inefficient equilibrium where all players hunt hare. Therefore, an increase in ambiguity, perhaps by playing someone from a different culture, has undesirable implications for both the stag hunt and bargaining coordination games.

\subsection{Previous Experimental Results}

le Roux and Kelsey (2016) compare the level of ambiguity when playing against a local or a foreign opponent in coordination games with multiple equilibria. Their participant pool consists of students at the University of Exeter in the UK and St. Stephen's College in New Delhi, India. They firstly run the experiment in India and then match the students in Exeter with both another Exeter student and a foreign opponent from the Indian sample. Students in the Exeter experiment are explicitly told that they are playing against students in India and are given some background information on the Indian students, e.g. that they are studying at a prestigious institution.

le Roux and Kelsey (2016) find no difference in the level of ambiguity when playing a local or foreign opponent. They offer the following reasons for this. Firstly, part of the experiment uses a within-subjects design where players face both a local and foreign opponent. Participants may have simply wanted to appear consistent in their choices against different opponents. In addition, some students were worried about appearing racist if they change their behaviour towards the foreign opponents. We can get around this first point by using a between-subjects design so that students are faced with either an opponent from their own culture or a different culture, but not both. 
However, le Roux and Kelsey (2016) also point out that participants may have found it easy to conceptualise the foreign students and thought they were the same as any other students due to increasing globalisation. As universities in the UK have become very international, students are used to mingling with people from many different cultures and probably see more similarities than differences with their fellow students. This point is difficult to control for and can only be dealt with by extending the sample to non-students who perhaps have less interaction with others from abroad. Such an extension is a promising avenue for future work.

\section{Experimental Design}

We tested whether players from the same cultural background coordinate better when playing strategic games, such as a stag hunt and a bargaining game. As the probabilities of the opponent's decision were unknown in these games, the decision environment was one of ambiguity rather than risk. Players should experience more ambiguity when playing against someone from a different culture as they are less familiar with the social norms of that culture. As such, we predicted that players from different cultures will prefer safer strategies and therefore choose less efficient outcomes in coordination games.

We ran a between-subjects design where players faced either someone from their own culture or someone a different culture, but not both. This was to remove the confound of participants wanting to appear consistent against different opponents, as noted by le Roux and Kelsey (2016). All participants played either a one-shot stag hunt game or a one-shot bargaining game. The reason we chose one-shot games was to make the decisions highly salient for the participants and avoid wealth effects in future rounds. We also wanted to avoid participants hedging risk between the two games, 
which is why each participant only played either the stag hunt or bargaining game, not both.

We recruited East Asian and British students to the Finance and Economics Experimental Laboratory (FEELE) at the University of Exeter. Using ORSEE (Greiner, 2004), we recruited participants based on surnames, with a mixture of East Asian and English surnames invited to sessions. We verified that all of the participants with East Asian surnames were East Asian by checking their responses to a follow-up questionnaire and did the same for participants with English surnames. A small number of participants with English surnames came from other individualistic English-speaking countries such as Australia and the United States. All of the participants with East Asian surnames were in fact from East Asian backgrounds, with the vast majority coming from China and a small number from Vietnam, Thailand, and Hong Kong.

We ran two different treatments, which are summarised below:

Treatment One: The opponent was from the same culture, which was achieved by inviting either all East Asian or all British participants to sessions.

Treatment Two: The opponent was from a different culture. Here, we invited a mixture of East Asian and British participants and matched them against each other.

Figure 3 shows the number of participants per treatment per culture. 
Figure 3: Number of Participants per Treatment per Culture

\begin{tabular}{|c|c|c|}
\hline & East Asian & British \\
\hline Treatment One: Same Culture & 32 & 28 \\
\hline Treatment Two: Different Culture & 32 & 32 \\
\hline
\end{tabular}

The main reasons for choosing East Asians and British were that the two cultures have very different social norms and that they have obvious differences in physical appearance. To avoid experimenter demand effects ${ }^{4}$, we used physical appearance to subtly show the cultural identity of the participants. This was achieved by telling participants they were randomly matched with another player who was seated on the other side of the room. However, to preserve anonymity we did not reveal who on the other side of the room they were matched with.

Therefore, in the East Asian-only and British-only sessions, the participants were matched with someone from their own culture. In the different-culture treatments, East Asians were seated on one side of the room and British on the other so that participants were matched with someone from a different culture. We ran two sessions here to swap which side of the room the Asians and British were seated on, in case this had any effect on their behaviour. There were no significant differences in behaviour between these sessions.

Given the large number of East Asian and British students studying at the university, we did not believe that having only East Asian or British students on one side of the room would feel unusual for the participants. However, we tested for

\footnotetext{
4 Brislin and Lonner (1973, p. 70) note that experimenter demand effects, or "courtesy bias", are particularly prevalent in Eastern cultures, where participants like to please the experimenter.
} 
experimenter demand effects by asking participants what they thought the experiment was about in a follow-up questionnaire, in the spirit of Benjamin et al (2010).

The experiment consisted of three stages: priming, stag hunt game or bargaining game, and follow-up questionnaire. All of the stages were run on computer terminals using z-Tree (Fischbacher, 2007). Full instructions for the experiment are available in Appendix One. Participants were given each set of instructions separately for each stage of the experiment.

\subsection{Priming}

Players were primed before taking part in the game, in order to make their cultural identities salient. We used a questionnaire to subtly get participants thinking about their own culture (Shih et al, 1999). This type of priming avoids inducing any particular stereotype which may affect behaviour. For example, showing American participants the Statue of Liberty may induce a feeling of freedom. Inducing stereotypes is dangerous as stereotypes can sometimes be misleading (Hsee and Weber, 1999). Instead, by completing a questionnaire, participants think about the people they know and social norms of their culture rather than stereotypes. The questions we used in the priming stage were intended to get participants thinking of their friends and family back home, and were as follows:

What year of study are you in at Exeter?

How many full years have you lived in the UK?

How often do you talk to people from your home country here in Exeter?

Do you live with your family during term time? 
If you answered "no" above, how many trips do you make to visit your family each year?

\subsection{Stag Hunt Game}

Our simple 2-player stag hunt game is illustrated below in Figure 4. Players had two strategies to choose from, which we label as "1" and "2". We kept the labels neutral, rather than calling the strategies "hunt hare" or "hunt stag". This is because the descriptive labels may be interpreted in a very different way by people from different cultures. The payoffs in Figure 4 are given in Experimental Currency Units (ECU), which were converted into pounds after the experiment.

Figure 4: Stag Hunt Game

\begin{tabular}{c|c|c|c|}
\multicolumn{3}{c}{} & \multicolumn{3}{c}{ Other Player's Choice } \\
\cline { 2 - 4 } \multicolumn{1}{c|}{} & & $\mathbf{2}$ & $\mathbf{1}$ \\
\cline { 2 - 4 } Your & $\mathbf{2}$ & 60,60 & 0,40 \\
\cline { 2 - 4 } Choice & $\mathbf{1}$ & 40,0 & 40,40 \\
\cline { 2 - 4 } & & &
\end{tabular}

\subsection{Bargaining Game}

The bargaining game involved a surplus of 40 ECU to be shared between each pair of participants. Each participant needed to decide how much of the 40 ECU to demand for themselves before knowing the decision of their opponent. If the total demands exceeded 40 , both players received zero. If the total demands were less than or equal to 40 , each player received the amount they demanded. However, participants had only four options in the amount they could demand, and there was no obvious focal point. This means that social norms become important in trying to determine what the opponent will choose. The bargaining game is illustrated in Figure 5. 
Figure 5: Bargaining Game

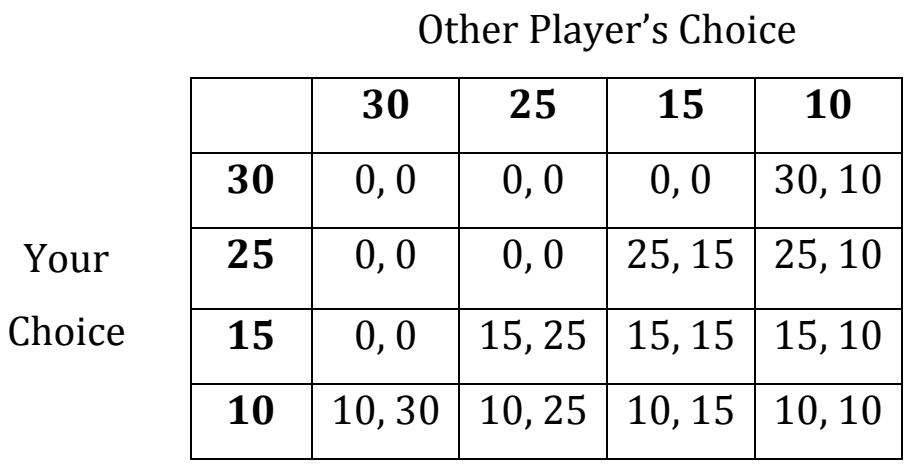

\subsection{Follow-up Questionnaire}

Once the game was complete, the participants were shown the decisions of their opponent and their total payoff from the experiment. After payoffs were revealed, the experiment was concluded with a demographic questionnaire, to control for other factors that could be driving behaviour. The questionnaire included a few questions about cultural background to verify where the participants were born and raised. We also asked participants for their predictions about their opponent's behaviour when playing the game. This was to see whether there was a difference in expectations when playing someone from another culture. The entire set of questions in the follow-up questionnaire can be found in Appendix Two.

\section{Results}

Figure 6 shows some summary statistics of our sample. While age was quite similar across cultures, the East Asian sample contained a higher proportion of females than the British sample. The East Asian sample also contained a slightly higher proportion of business majors. On average, East Asian students had lived in the UK for 3.30 years, compared to an average of 17.43 for the British students, most of whom had lived in Britain for their entire lives. This indicates that the East Asian students were 
indeed exposed to a different cultural upbringing than the British. We controlled for all of these demographic variables in our regression analysis.

Figure 6: Summary Statistics

\begin{tabular}{|l|l|l|}
\hline Averages & East Asian & British \\
\hline Age (years) & 21.06 & 19.73 \\
\hline Percentage of Females & $79.69 \%$ & $33.33 \%$ \\
\hline Percentage of Business Majors & $82.54 \%$ & $75.00 \%$ \\
\hline Years in the UK & 3.30 & 17.43 \\
\hline
\end{tabular}

\subsection{Stag Hunt Game}

The results from the stag hunt game are reported below in Figures 7 and 8 . Here we not only see a difference between the same culture and mixed culture treatments, but we find a difference in behaviour between cultures. When the British students were faced with an East Asian opponent, they were less likely to go for the payoff dominant outcome than when faced with a British opponent ( $p=0.079$ using a Mann-Whitney $U$ test $^{5}$ ). However, the East Asian students were no less likely to choose the payoff dominant outcome when faced with a British opponent compared to an East Asian opponent. In fact, the proportion of East Asians choosing each option was exactly the same in each treatment.

We also checked the expectations data from our follow-up questionnaire. While the East Asian students did not differentiate between the same culture and mixed culture treatments, the British students were less likely to expect East Asian students to

\footnotetext{
5 Throughout this paper, we use a Mann-Whitney $U$-test to determine whether the samples are statistically different.
} 
choose the payoff dominant outcome compared to other British. This suggests that the British may have been relying on a cultural stereotype of East Asians being cautious (Hsee and Weber, 1999).

Figure 7: Proportion of British and East Asian students choosing stag or hare when faced with an opponent from the same culture

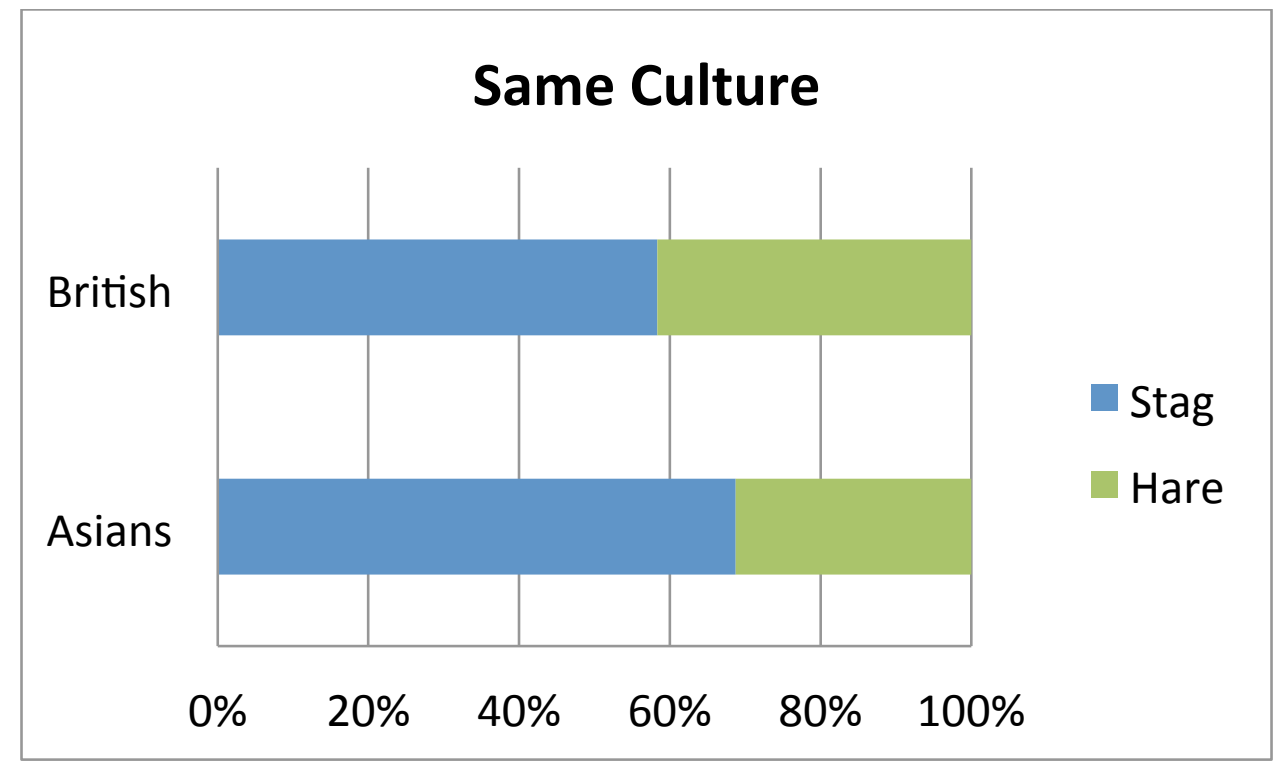

Figure 8: Proportion of British and East Asian students choosing stag or hare when faced with an opponent from a different culture

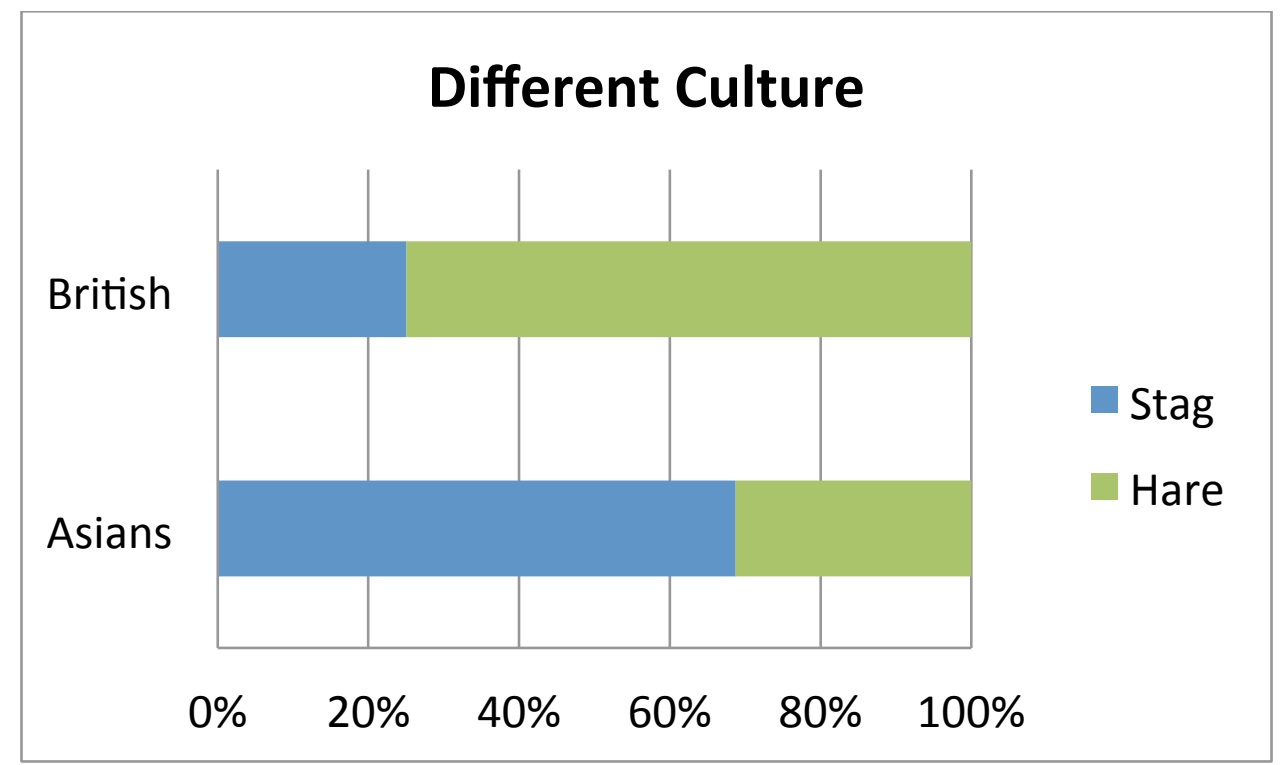




\subsection{Stag Hunt Game: Regression Analysis}

We ran a probit regression on whether or not the participants chose to hunt stag. Our dependent variable was binary, hunting stag $=1$ and hunting hare $=0$. We controlled for the following variables: culture (East Asian =1, British $=0$ ), age in years, gender (female $=1$, male $=0$ ), subject major (business major $=1$, otherwise $=0$ ), years in the UK, an interaction term for culture and gender (East Asian female $=1$, otherwise $=$ 0 ), and treatment (same culture $=1$, different culture $=0$ ). The coefficients from this regression are presented below in Figure 9.

Figure 9: Coefficients from Probit Regression on Hunting Stag 6

\begin{tabular}{lc}
\hline & Coefficients \\
\hline East Asian & 0.581 \\
& $(0.932)$ \\
Age & $0.410^{* *}$ \\
& $(0.177)$ \\
Female & 0.183 \\
& $(0.536)$ \\
Business Major & -0.513 \\
& $(0.527)$ \\
Years in UK & -0.003 \\
& $(0.045)$ \\
East Asian Female & -0.653 \\
& $(0.903)$ \\
Same Culture & 0.601 \\
Constant & $(0.368)$ \\
\hline
\end{tabular}

According to the regression results, culture (being East Asian or British) does not influence the choice to hunt stag rather than hare. This is in contrast to the British

\footnotetext{
${ }^{6}$ Robust standard errors are given in parentheses. Significance at the $90 \%, 95 \%$, and $99 \%$ level of confidence is indicated with $*, * *$, and $* * *$, respectively.
} 
student's predictions that East Asians would be less likely to choose stag. Age is the only significant demographic variable, with a positive effect on choosing stag.

\subsection{Bargaining Game}

Similarly to the stag hunt results, we also obtain a cultural difference in the bargaining game. The results are presented below in Figures 10 and 11. East Asians demanded slightly less of the pie when faced with a British opponent compared to the all-East Asian treatment, although this difference is not significant $(p=0.389)$. On the other hand, British demanded more when faced with an East Asian opponent compared to the all-British treatment, which is a significant result $(p=0.010)$. The British also contrasted the theoretical prediction that people will choose safer options when faced with an opponent from a different culture. However, the coordination worked well, with the British demanding more and East Asians demanding less when faced with an opponent from a different culture.

According to our expectations data from the follow-up questionnaire, the British students expected East Asian students to claim less of the pie than other British students. This suggests that the cultural difference in the bargaining game could have been driven by social norms. Perhaps the East Asian students felt the need to be politer towards the British students than the other East Asian students, as they considered themselves guests in the UK. The British students may have expected East Asians to be polite towards them, based on their personal experiences, and therefore expected to be able to claim more of the pie. 
Figure 10: Proportion of British and East Asian students choosing each bargaining game option when faced with an opponent from the same culture

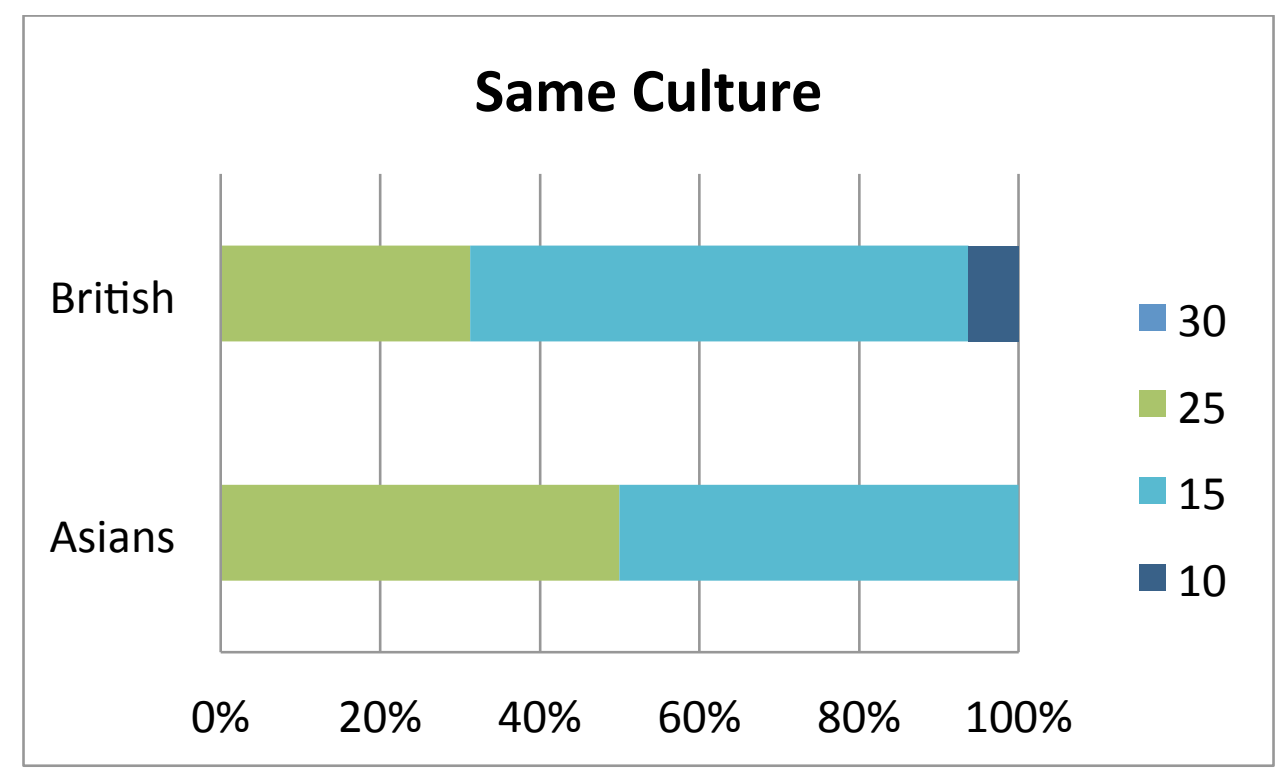

Figure 11: Proportion of British and East Asian students choosing each bargaining game option when faced with an opponent from a different culture

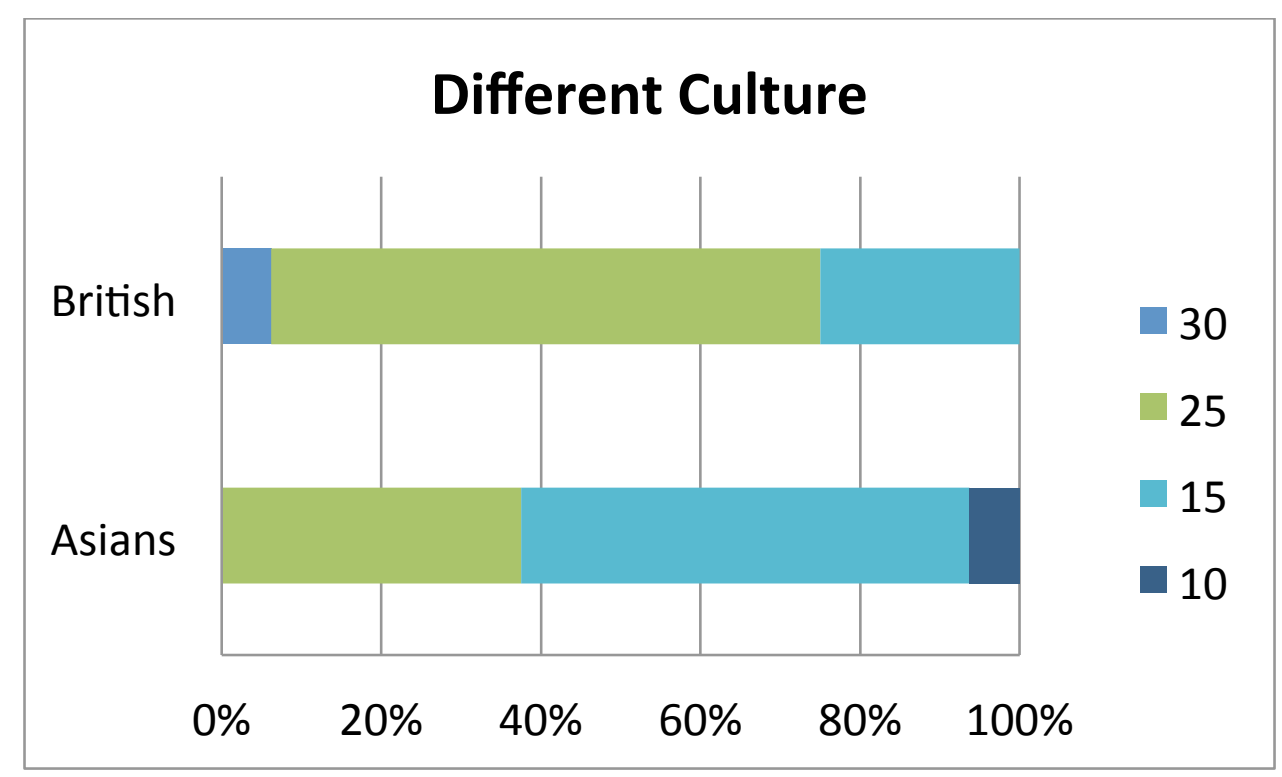

\subsection{Bargaining Game: Regression Analysis}

Similarly to the stag hunt, we ran a probit regression on choices in the bargaining game. Again, our dependant variable was binary, with a risky choice (25 or 30) = 1 and a safe 
choice $(10$ or 15$)=0$. We controlled for the following variables: culture (East Asian $=1$, British $=0$ ), age in years, gender (female $=1$, male $=0$ ), subject major (business major $=$ 1 , otherwise $=0$ ), years in the UK, an interaction term for culture and gender (East Asian female $=1$, otherwise $=0)$, and treatment ( same culture $=1$, different culture $=0)$. The coefficients from this regression are presented below in Figure 12. None of the coefficients are statistically significant in this regression.

Figure 12: Coefficients from Probit Regression on Bargaining Game Choice ${ }^{7}$

\begin{tabular}{lc}
\hline & Coefficients \\
\hline East Asian & -1.327 \\
& $(0.931)$ \\
Age & -0.037 \\
& $(0.067)$ \\
Female & 0.262 \\
& $(0.504)$ \\
Business Major & -0.285 \\
& $(0.393)$ \\
Years in UK & -0.026 \\
& $(0.044)$ \\
East Asian Female & 0.796 \\
& $(0.843)$ \\
Same Culture & -0.437 \\
Constant & $(0.337)$ \\
\hline
\end{tabular}

\section{Discussion}

Why, then, do the East Asians differentiate based on the identity of the opponent in the bargaining game but not the stag hunt? The stag hunt game is more straightforward and has an obvious focal point of both players going for the payoff dominant outcome. Perhaps the East Asians thought this choice was obvious regardless

\footnotetext{
${ }^{7}$ Robust standard errors are given in parentheses. Significance at the $90 \%, 95 \%$, and $99 \%$ level of confidence is indicated with $*, * *$, and $* * *$, respectively.
} 
of the opponent, whereas the bargaining game required more thought. However, we cannot glean any evidence of longer response time in the bargaining game compared to the stag hunt in our z-Tree output. Similarly, East Asians may interpret the two games in different ways, with the stag hunt being focused on efficiency while the bargaining game is about fairness. Identity may then play a greater role when making decisions about fairness as opposed to efficiency. We now turn to consider both social preferences and expectations of the opponent's behaviour as potential explanations for our results.

\subsection{Stereotypes}

The British appear to be more careful in the stag hunt but more risk taking in the bargaining game, when faced with a foreign opponent. While this behaviour may seem odd, we can make sense of this by thinking about stereotypes. The British may expect East Asians to choose the safer options in both games, which would mean that the British should also play it safe in the stag hunt but take a risk in the bargaining game. When looking at the expectations data, East Asian participants do not show much difference between treatments. However, the British expect the East Asians to demand much less of the pie than other British. The British also expect East Asians to be more likely to choose the safe option in the stag hunt compared to other British.

According to the follow-up questionnaires, a few people had an inkling that the experiment was about ethnicity. For example, when asked for aspects of the opponent's identity they considered in making their decision, one participant commented "Their gender, their race/ethnicity, their nationality." Although only a few people (four in total) guessed that the experiment was about ethnicity, others may have subconsciously picked up on cultural stereotypes. This is especially true given our priming questionnaire at the beginning of the experiment. While the questionnaire was intended 
to induce social norms, rather than stereotypes, there is a possibility that the questionnaire heightened students' susceptibility to stereotypes.

The most likely explanation for the results seems to be that the British students expected the East Asians to behave cautiously in both games. In other words, British students expected that East Asian students would take the safe option in the stag hunt and demand less of the pie in the bargaining game. Is this stereotype true? To investigate this, we restrict ourselves to the same culture treatments, where the decisions are less complicated by trying to figure out the cultural norms of the opponents.

When looking at the same culture treatments, East Asians are more likely to hunt stag than British and also demand more of the pie in the bargaining game. This means that a stereotype of East Asians being cautious is not only misleading, but has real effects on behaviour. Even the East Asian students appear to be affected by their own stereotype in the bargaining game, where they demand less of the pie against British students than in the same culture treatment. East Asian students may lower their demands against the British students because they expect the British students to demand more, based on the stereotype that East Asians are cautious. These results are in-line with Hsee and Weber's (1999) study that finds Chinese to be more risk seeking than Americans, even though both groups predicted the opposite, and also Shih et al's (1999) finding that even stereotypes about one's own culture can affect behaviour.

\subsection{Norms vs. Identity}

We can now consider whether cultural norms or the opponent's identity had the greatest influence on behaviour. As we observe a difference in behaviour between 
British and East Asians in many of the same culture treatments, we can speculate that cultural norms play a part in the decision making process. However, the difference in behaviour between the same culture and different culture treatments shows that identity also comes into play. Chuah et al (2007) also find cultural differences both when interacting within national groups and with those from another group, when looking at ultimatum game responses of Malaysian Chinese and UK participants. This suggests that both cultural norms and the opponent's identity play a part in interactive decision making.

\subsection{Efficiency}

We can also consider whether playing someone from a different culture improves or hinders efficiency. For both games, the payments are higher in the same culture treatments than the different culture treatments. However, for the bargaining game we notice fairly good coordination between East Asians and British in the different culture treatments. British increase their demands when facing an East Asian opponent compared to another British opponent, while East Asians lower their demands against the British. The players seem to be using cultural stereotypes to predict each other's behaviour and choose their action accordingly. Interestingly, players perform better by behaving according to the stereotype, even if the stereotype is untrue.

On the other hand, coordination is hindered in the different culture treatments in the stag hunt game. While East Asians tend to go for the payoff dominant choice, British get the wrong impression by believing East Asians will be cautious and choose the certain outcome. Therefore, British tend to choose the certain outcome, based on a misleading stereotype, when they could do better by choosing the payoff dominant 
outcome. Therefore, stereotypes may sometimes be a useful guide to behaviour when there is little else to base decisions on, but can also harm efficiency if the opponents do not behave according to their stereotypes.

\subsection{Social Preferences}

While we have considered expectations of the opponent's behaviour based on their identity, we have yet to mention how social preferences may differ by culture. Perhaps the players care more about each other's payoffs when they are from the same culture. Chen and Chen (2011) consider an other-regarding parameter that increases when players share a common group identity. While Chen and Chen (2011) find an improvement in coordination when players share a group identity, it is unclear whether this is because they care more about each other's payoff, or because they believe the other player is more likely to choose the payoff dominant outcome when they come from the same group. Reciprocity is likely to feature in Chen and Chen's (2011) experiment as the participants helped each other in a task before taking part in the game. Therefore, expectations of reciprocity may have improved the coordination, rather than altruistic feelings towards those from the same group.

Separating beliefs from social preferences is also difficult in our experiment. However, when reading through responses to our follow-up questionnaire, the players appear to be trying to maximise their own payoff, with little regard for the other player. For example, many players mention something along the lines of "I wanted to guarantee a payment regardless of the other player", when asked "how did you decide what option to choose?" 
Worth noting, is that motivations for behaviour are likely to be different in the stag hunt than the bargaining game. The stag hunt is a game of cooperation while the bargaining game is one of competition. In the stag hunt, the option that maximises the player's payoff also maximises the opponent's payoff. Therefore, decisions are more likely to be driven by expectations of the other's behaviour than social preferences. In contrast, the bargaining game introduces a conflict between the player's payoff and the opponent's payoff. Here social preferences are more likely to play a role, as the player must decide how much they care about their own payoff relative to the opponent's payoff.

Cultural differences in the way in-groups and out-groups are formed and defined may also impact the level of altruism players feel towards each other. Forming a group takes longer in collectivist cultures as bonding is necessary, whereas individualists have many superficial interactions and perhaps in-groups are formed more readily (Triandis, 1989). This means that students from collectivist cultures, such as many East Asian countries, may perceive all others as out-groups as their in-groups only include close friends and family and are not extended to nationality. For this reason, the students from collectivist cultures could be less susceptible to group identity effects. This is a research question for the future, along with experiments to isolate the effects of altruism versus expectations of the opponent's behaviour.

\subsection{Design Limitations}

Another possibility is that participants did not consider the cultural identity of their opponent in decision making and treated the opponent simply as "another student". In Eichberger et al's (2008) experiment, the participants are given descriptions of the granny and game theorist, which make them more believable and 
easier to imagine. Perhaps having students of a different culture on the other side of the room was not enough to distinguish a cultural identity. However, le Roux and Kelsey (2016) give their participants background information about the Indian students but still find no difference in the level of ambiguity against a foreign or home opponent. Eichberger et al (2008) find that other students are also a source of ambiguity, with other students being perceived as more ambiguous than the game theorist and just as ambiguous as the granny. An interesting idea for future research would be to combine the cultural identity of the opponent with further information, such as "the opponent is studying game theory" to see how the two components of identity interact.

As part of the follow-up questionnaire we ask participants whether they considered the identity of their opponent when making their decision. East Asians are slightly more likely to answer this question with "yes" but there appears to be some misunderstanding about what the question was asking. For example, when asked what aspects of the opponent's identity they considered, several students talk about mutual benefit or what choice they thought the opponent would take. According to our questionnaire responses, identity is actually considered more in the same-culture treatments than the different-culture treatments. However, very few students mention culture as an aspect of identity they considered.

We also need to consider whether our priming questionnaire had a differential impact on British students compared to East Asian students. The questionnaire probably felt quite normal for international students, with questions about how long you have lived in the UK and how often you speak to people from your home country. However, this questionnaire may have felt quite strange, or had little or no impact, for the British students. In addition, the questionnaire may have primed aspects of identity 
other than culture, such as a sense of family. Priming a sense of family could change the mood of East Asian students in a different way to British students. For example, East Asian students may feel sad when family is primed as they are probably very far away from their families, while British students are a lot closer.

These concerns highlight a key caveat with our data, sample bias. The sample bias comes from comparing the behaviour of home students with international students, who may be inherently different in personality. Our results may be driven by differences between home and international students, rather than cultural differences. Our sample also only includes students. Therefore, our results cannot be used to generalise to entire cultures.

\section{Conclusions}

We expected that players would experience more ambiguity when faced with an opponent from a different culture and therefore choose safer options in coordination games. This is because players may find it harder to predict each other's behaviour when they do not share similar social norms.

In the stag hunt game, the British students tended to go for the safe, risk dominant, outcome against the East Asians, even though most East Asians still tried to achieve the payoff dominant outcome. On the other hand, in the bargaining game the British students increased their demands against the East Asians while East Asians lowered their demands against the British. One likely reason for this is a cultural stereotype of East Asians being cautious. Based on our results, this stereotype was proven to be misleading. 


\section{Appendix One: Experiment Instructions}

\section{Instructions}

You are about to take part in an experiment. Your payoff from this experiment will depend on the decisions you make during the experiment. Therefore it is important that you carefully read and understand these instructions.

Please do not communicate with the other participants at any stage during the experiment. If you have a question, please raise your hand and the experimenter will assist you.

Your earnings from the experiment will be in Experimental Currency Units (ECU). Each ECU is worth $£ X X$ ( $£ 0.05$ for stag hunt, $£ 0.20$ for bargaining game). After the experiment, your earnings will be converted into pounds, and you will be paid anonymously in cash before you leave the room. You will also receive a $£ 2$ show-up fee, in addition to any money earned during the experiment.

The experiment will start with a questionnaire which will shortly appear on the computer screen. Please complete the questions and then click the "OK" button at the bottom of the screen.

After everyone has completed the questionnaire, instructions will be handed out for the next stage of the experiment. 


\section{$\underline{\text { Stag Hunt Instructions }}$}

In the next stage of the experiment, you will play the game described below. You will be randomly matched with another player who is sitting on the other side of the room to you.

The game consists of a choice between 1 and 2. Your payoff depends on both your own choice and the choice of the player you are matched with, who is sitting on the other side of the room.

The payoff table for this game is illustrated below. The numbers in the table correspond to your payoffs in ECU, for every possible combination of choices by you and the other player. The first number in each cell is your payoff and the second number is the other player's payoff.

If both you and the other player choose 2 , you each receive a payoff of 60 ECU. If both players choose 1 , you each receive a payoff of 40 . If one player chooses 2 while the other chooses 1 , the player choosing 2 receives 0 while the player choosing 1 receives 40 .

Please input your choice of 1 or 2 into the computer when asked to do so. You will not know the choice of the other player until after you have made a decision.

If you have a question, please raise your hand and the experimenter will assist you.

Other Player's Choice

\begin{tabular}{l|c|c|c|}
\cline { 2 - 4 } \multicolumn{1}{c|}{} & & $\mathbf{2}$ & $\mathbf{1}$ \\
\cline { 2 - 4 } Your & $\mathbf{2}$ & 60,60 & 0,40 \\
\cline { 2 - 4 } Choice & $\mathbf{1}$ & 40,0 & 40,40 \\
\hline
\end{tabular}




\section{Bargaining Game Instructions}

In the next stage of the experiment, you will play the game described below. You will be randomly matched with another player who is sitting on the other side of the room to you.

You and another player are allocated 40 ECU to share between you. You need to decide how much of the 40 ECU you will demand for yourself and the other player will do the same. If the total demands from you and the other player exceed 40 ECU, you will both receive 0 . If the total demands are less than or equal to 40 , each of you will receive the amount you demanded.

The payoff table for this game is illustrated below. The numbers in the table correspond to your payoffs in ECU, for every possible combination of choices by you and the other player. The first number in each cell is your payoff and the second number is the other player's payoff.

As an example, if you choose 25 and the other player chooses 15, the total demands are 40. In this case, you will receive 25 and the other player will receive 15 . However if you choose 25 and the other player also chooses 25 , the total demands are 50 . In this case, you will both receive 0 .

As another example, if you choose 10 and the other player chooses 15, the total demands are 25 , which is less than 40 . In this case, you will receive 10 and the other player will receive 15 .

Please input your choice of $10,15,25$, or 30 into the computer when asked to do so. You will not know the choice of the other player until after you have made a decision.

If you have a question, please raise your hand and the experimenter will assist you.

Other Player's Choice

\begin{tabular}{|c|c|c|c|c|c|}
\hline \multicolumn{1}{c|}{} & $\mathbf{3 0}$ & $\mathbf{2 5}$ & $\mathbf{1 5}$ & $\mathbf{1 0}$ \\
\hline \multirow{4}{*}{$\begin{array}{c}\text { Your } \\
\text { Choice }\end{array}$} & $\mathbf{3 0}$ & 0,0 & 0,0 & 0,0 & 30,10 \\
\cline { 2 - 6 } & $\mathbf{1 5}$ & 0,0 & 0,0 & 25,15 & 25,10 \\
\hline & $\mathbf{1 0}$ & 10,30 & 10,25 & 10,15 & 10,10 \\
\hline
\end{tabular}




\section{Appendix Two: Follow-up Questionnaire}

Please answer the following questions and click the "OK" button when complete.

How did you decide what option to choose?

What did you think the other player would choose?

Did you consider the identity of the other player when making your decision?

If you answered "yes" above, what aspects of the other player's identity did you consider?

What do you think this experiment was about? (Optional)

- OK Button -

Please answer the following questions and click the "OK" button when complete.

Age (in years):

Gender:

Subject major:

Nationality:

Nationality(ies) of your parents:

Country of birth:

Native language:

Second languages:

- OK Button - 


\section{References}

Akerlof, G. A., \& Kranton, R. E. (2000). Economics and Identity. The Quarterly Journal of Economics, 115:3, 715-753.

Benjamin, D. J., Choi, J. J., \& Strickland, A. J. (2010). Social Identity and Preferences. American Economic Review, 100:4, 1913-1928.

Brislin, R. W., \& Lonner, W. J. (1973). Cross-Cultural Research Methods. New York, London: Wiley-Interscience.

Chen, R., \& Chen, Y. (2011). The Potential of Social Identity for Equilibrium Selection. American Economic Review, 101:6, 2562-2589.

Chen, Y., Li, S. X., Liu, T. X., \& Shih, M. (2014). Which Hat to Wear? Impact of Natural Identities on Coordination and Cooperation, Games and Economic Behavior, 84, 58-86.

Chuah, S. H., Hoffman, R., Jones, M., \& Williams, G. (2007). Do cultures clash? Evidence from cross-national ultimatum game experiments. Journal of Economic Behavior \& Organization, 64:1, 35-48.

Eichberger, J., \& Kelsey, D. (2002). Strategic Complements, Substitutes, and Ambiguity: The Implications for Public Goods. Journal of Economic Theory, 106:2, 436-466.

Eichberger, J., Kelsey, D., \& Schipper, B. (2008). Granny Versus Game Theorist: Ambiguity in Experimental Games. Theory and Decision, 64:2, 333-362.

Fershtman, C., \& Gneezy, U. (2001). Discrimination in a Segmented Society: An Experimental Approach. The Quarterly Journal of Economics, 116:1, 351-377.

Fischbacher, U. (2007). z-Tree: Zurich Toolbox for Ready-made Economic Experiments. Experimental Economics, 10:2, 171-178.

Geisinger, A. (2004). A Group Identity Theory of Social Norms and Its Implications. Tulane Law Review, 78:605, 605-652.

Greiner, B. (2004). An Online Recruitment System for Economic Experiments. In K. Kremer, \& V. Macho. (Eds.), Forschung und wissenschaftliches Rechnen, (2003.). GWDG Bericht 63, Göttingen : Ges. für Wiss. Datenverarbeitung, 79-93.

Harrison, G. W., Humphrey, S. J., \& Verschoor, A. (2009). Choice under Uncertainty: Evidence from Ethiopia, India and Uganda. The Economic Journal, 120:543, 80104.

Harrison, G. W., List, J. A., \& Towe, C. (2007). Naturally Occurring Preferences and Exogenous Laboratory Experiments: A Case Study of Risk Aversion. Econometrica, 75:2, 433-458.

Hofstede, G. (1980). Culture's Consequences: International Differences in Work-Related Values. Newbury Park (CA), London, New Delhi: Sage Publications. 
Hsee, C. K., \& Weber, E. U. (1999). Cross-National Differences in Risk Preference and Lay Predictions. Journal of Behavioural Decision Making, 12, 161-179.

Huyck, J. B., Battalio, R. C., \& Beil, R. O. (1990). Tacit Coordination Games, Strategic Uncertainty, and Coordination Failure. The American Economic Review, 80:1, 234-248.

le Roux, S., \& Kelsey, D. (2016). Dragon Slaying with Ambiguity: Theory and Experiments, Journal of Public Economic Theory, 19:1, 178-197.

Shih, M., Pittinsky, T. L., \& Ambady, N. (1999). Stereotype Susceptibility: Identity Salience and Shifts in Quantitative Performance. Psychological Science, 10:1, 8083.

Singh, T. B. (2012). A social interactions perspective on trust and its determinants, Journal of Trust Research, 2:2, 107-135.

Triandis, H. C. (1989). Cross-Cultural Studies of Individualism and Collectivism. In Berman, J. (Ed.) Nebraska Symposium on Motivation, 41-133. Lincoln: University of Nebraska Press.

Watson, W. E., \& Kumar, K. (1992). Differences in Decision Making Regarding Risk Taking: A Comparison of Culturally Diverse and Culturally Homogeneous Task Groups. International Journal of Intercultural Relations, 16:1, 53-65. 